\title{
Subject Visit End Day
}

National Cancer Institute

\section{Source}

National Cancer Institute. Subject Visit End Day. NCI Thesaurus. Code C88000.

The day of the week a subject visit has concluded. 